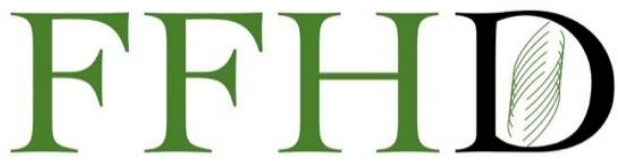

Functional Foods in Health and Disease

\title{
Cholesterol in virus entry into host cell: diet, phytosterols and statins
}

\section{Olimpio Montero}

Spanish National Council for Scientific Research (CSIC). Francisco Vallés Str., 8. 47151 - Boecillo (Valladolid). Spain

Corresponding author: Olimpio Montero, PhD, CSIC, Boecillo (Valladolid). Spain

Submission Date: January 25 ${ }^{\text {th }}, 2021$; Acceptance Date: March $1^{\text {st }}, 2021$; Publication Date: March $15^{\text {th }}, 2021$

Please cite this article as: Montero 0 . Cholesterol in virus entry into host cell: diet, phytosterols and stains. Functional Foods in Health and Disease 2021. 11(3): 104-115 DOI: https://www.doi.org/10.31989/ffhd.v11i3.780

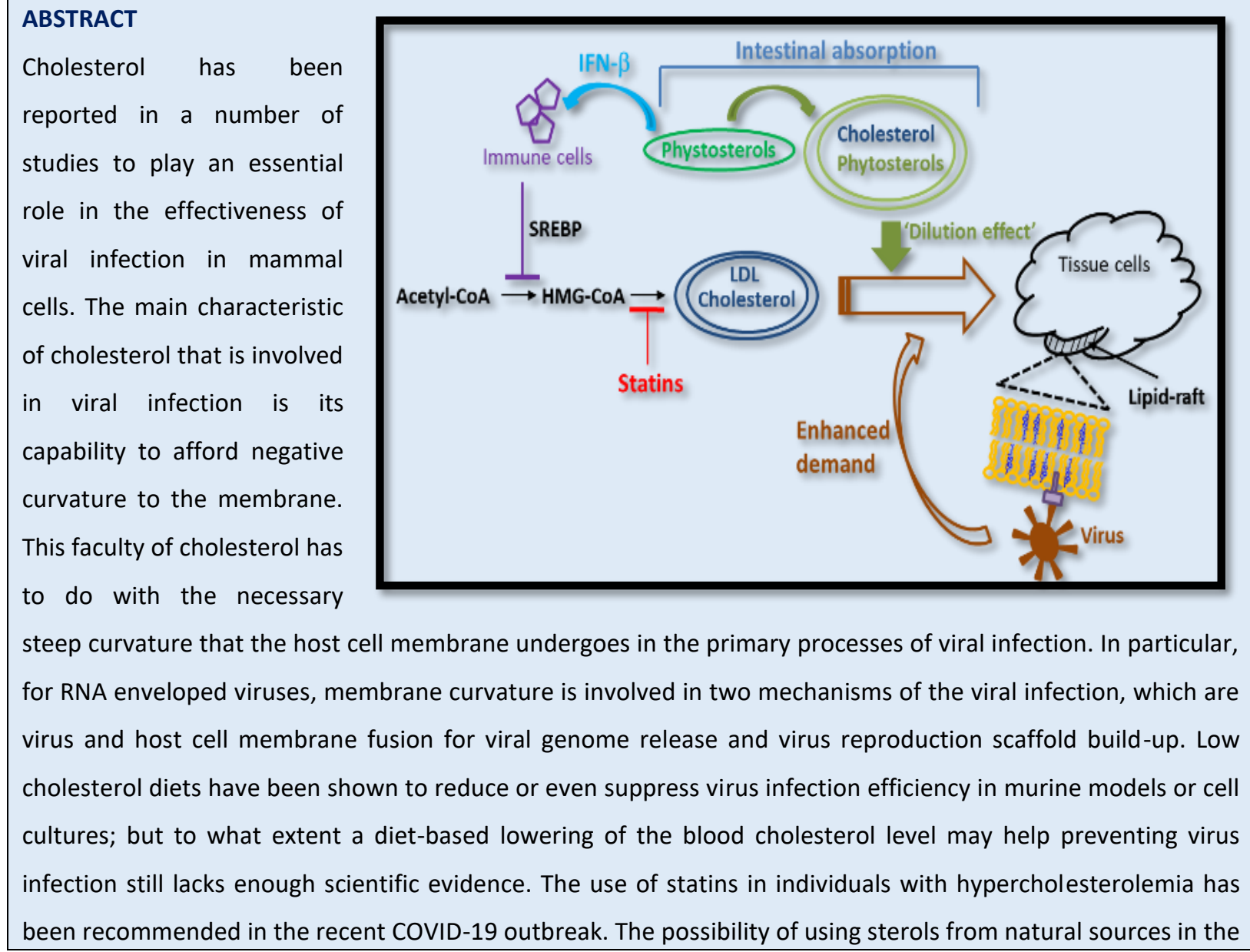


diet or in supplementary concentrates has been suggested to be an alternative to drop the circulating cholesterol. In this manuscript, the most relevant and recent bibliography on the aforementioned issues is reviewed.

Keywords: cholesterol, virus infection, membrane curvature, sterols, natural food sources

CFFC 2021. This is an Open Access article distributed under the terms of the Creative Commons Attribution 4.0 License (http://creativecommons.org/licenses/by/4.0)

\section{INTRODUCTION}

In spite of contradictory results have been reported in some studies, in particular for older people [1,2], cholesterol is widely known at present to be involved in certain pathological processes that affect the human health, especially those regarding cardiovascular risk, [3-6]. However, cholesterol is an essential component molecule of the biological membranes in mammals, besides being the precursor of other relevant molecules of the mammal metabolism like steroid hormones, bile acids and vitamin D [7-9].

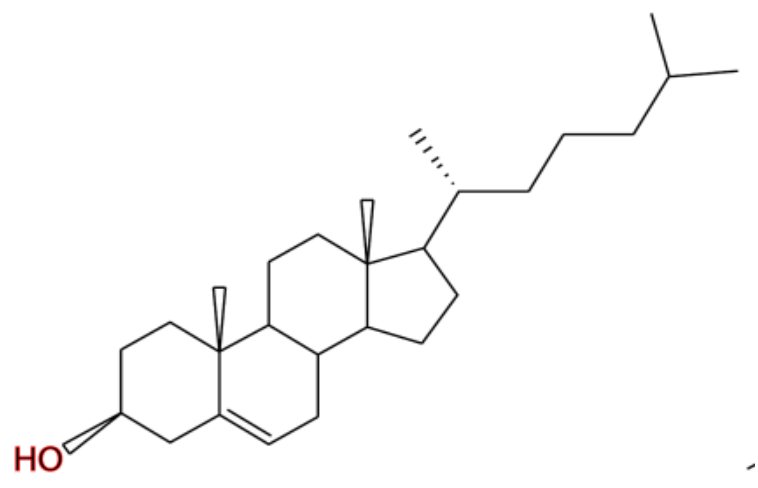

(3ß)-Cholest-5-en-3-ol (Cholesterol)

Figure 1. Schematic drawing of the chemical structure of the cholesterol molecule

The cholesterol molecule ((3- $\beta)$-Cholest-5-en-3ol, PubChem CID 5997) is a very low polar lipid composed of four hydrocarbon cycles with a hydroxyl group and a dimethyl-hexyl chain bound to different positions of the cycles (Figure 1). The cholesterol tetracyclic structure is embedded into the phospholipid acyl chain bulk of the membrane, whose fluidity, stability, through controlling the phospholipid packaging, and permeability regarding molecule flux across, the cholesterol contributes to regulate [10]. Every mammal cell is able to synthesise cholesterol through the mevalonate pathway, but about $80 \%$ of cholesterol is synthesised in the liver and the intestines, the remaining circulating cholesterol being acquired through the diet (Figure 2, scheme A). Because of the hydrophobic nature of the cholesterol, it is transported through the organism within plasma lipoproteins, namely very-low density lipoproteins (VLDL), low density lipoproteins (LDL) and the high density lipoproteins (HDL) (Figure 2, scheme B). VLDLP and LDL deliver the cholesterol cargo to the different tissues, whereas HDL is responsible to recycle the cholesterol in excess by transporting it backward to the liver; hence, they are commonly known as "bad cholesterol" (VLDL and LDL) and "good cholesterol" (HDL), respectively [11,12]. Under non-pathological conditions, the cholesterol metabolism is thoroughly regulated at the biosynthetic level in the liver (Figure 2, scheme A). However, cholesterol intake in excess may dysregulate its control mechanisms $[6,9,13]$. Recommended levels of cholesterol in blood are depicted in Table 1. 
Table 1. Recommended healthy levels of cholesterol in blood in its different forms as reported by the National Library of Medicine of the National Institutes of Health

(NLM-NIH, https://medlineplus.gov/cholesterollevelswhatyouneedtoknow.html)

\begin{tabular}{|l|l|l|}
\hline \multirow{2}{*}{ Cholesterol form } & \multicolumn{2}{|c|}{ Healthy level in blood } \\
& Men & Women \\
\hline Total & $125-200 \mathrm{mg} / \mathrm{dL}$ & $125-200 \mathrm{mg} / \mathrm{dL}$ \\
\hline LDL & $<100 \mathrm{mg} / \mathrm{dL}$ & $<100 \mathrm{mg} / \mathrm{dL}$ \\
\hline HDL & $\geq 40 \mathrm{mg} / \mathrm{dL}$ & $\geq 50 \mathrm{mg} / \mathrm{dL}$ \\
\hline
\end{tabular}

A low energy diet is recommended to avoid obesity and the risk of heat strokes. This diet, which includes vegetables and fruits as main intakes, is also the main dietary style to reduce cholesterol. A vegetarian diet style has been reported to intake 140 $\mathrm{mg} /$ day less of cholesterol than a non-vegetarian diet [6].

Cholesterol in virus infection: Because of cholesterol is an essential component of the animal cell membranes, the role played by cholesterol in virus infection has been matter of research over the last few decades [7-9]. In particular, enveloped RNA viruses have been found to hijack the host cell lipid metabolism to account for the cholesterol and other specific lipid demand for their replication scaffold build-up [14] (Figure 2, scheme C). Cholesterol is known to be a constituent of the virus membrane envelope, and transmembrane proteins inserted in specific domains of the host cell membrane known as lipid-rafts are preferred by the RNA viruses for docking to the infected cell during virus entry. Indeed, high cholesterol concentration in the micro-domain of the host membrane has been shown to be essential for viral and target cell membrane fusion in virus genome release into the cell, the cholesterol concentration acting as a pathway switch [15-17]. In
HIV-1 infection, the clustering of the virus envelope glycoproteins requires the interaction of the viral gp41 protein with cholesterol in the virus membrane, cholesterol acting as a molecular switch [18]. The angiotensin-converting enzyme 2 (ACE2), which is the binding protein for the severe acute respiratory syndrome coronavirus-1 and 2 (SARS-CoV-1 and 2) and other coronaviruses spike protein, was shown to be largely associated to lipid-rafts enriched in cholesterol $[14,16,19,20]$. Host cell cholesterol plays also an essential role in the infection by Flaviviruses $[14,21]$.

The recent COVID-19 outbreak has prompted urgent research on the mechanisms used by the severe acute respiratory syndrome coronavirus 2 (SARS-CoV-2) to infect the cells as well as the factors involved in such mechanisms. Different studies have shown that cholesterol content and metabolism pathways related to it are of primary relevance for virus entry into the cell. The C-terminal fragment of the sterol regulatory element-binding protein 2 (SREBP2), which is a transcription factor involved in cholesterol homeostasis, has been found to be present in blood of COVID-19 patients, and its presence is postulated to be a factor inducing the inflammatory response to infection that leads to the 
cytokine storm [22]. The S1 subunit of the SARS-CoV-

2 spike protein has been shown to bind cholesterol and other HDL components in order to facilitate virus entry, this mechanism being mediated by the highdensity lipoprotein (HDL) scavenger receptor B type 1 (SR-B1) [23]

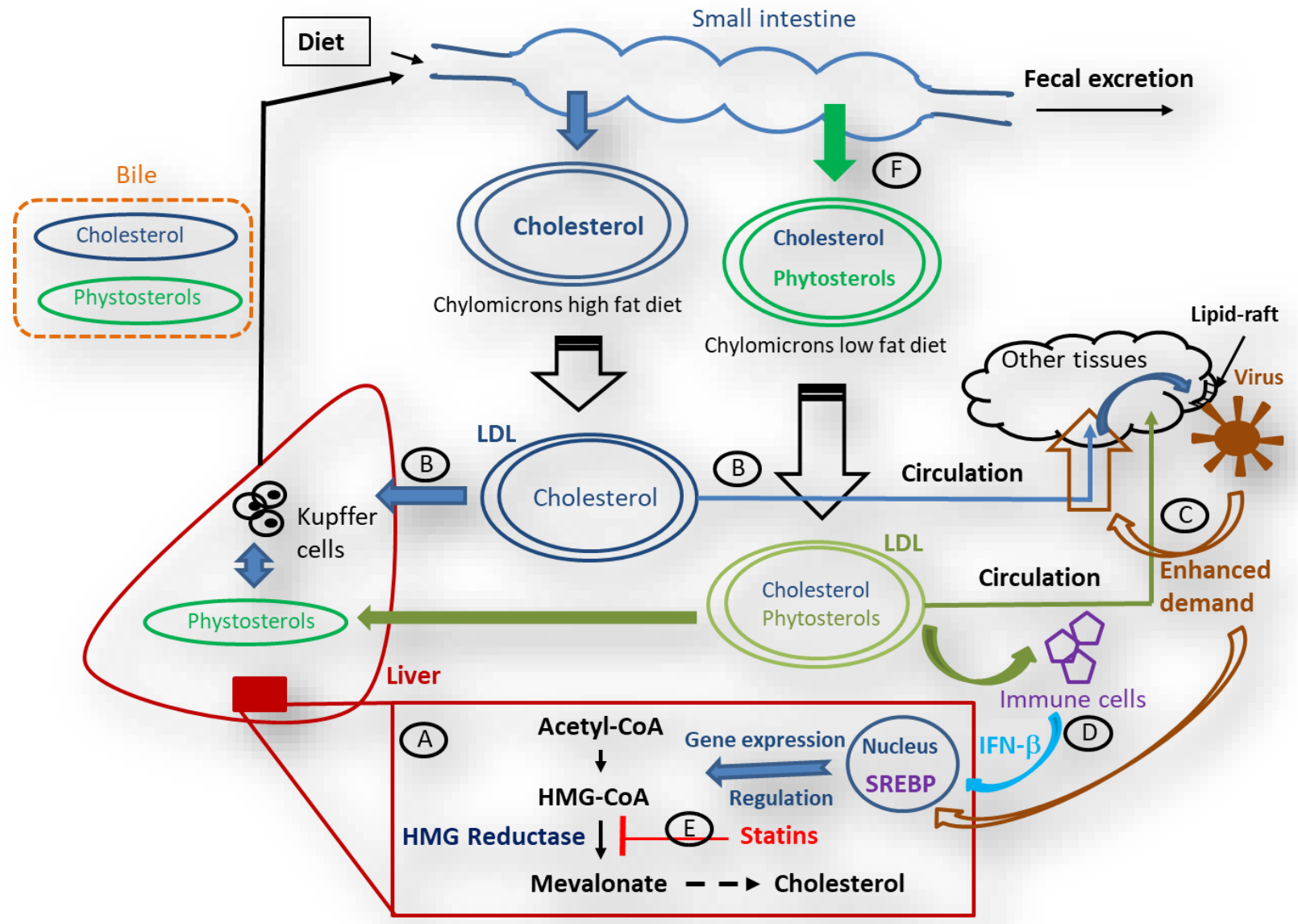

Figure 2. Schematic drawing of the interaction of cholesterol metabolism with and its regulation by viral infection, and the positive intervention of statins and phytosterols to counteract the viral subversion of the cholesterol metabolism. Letter-indicated sections (A-F) of the figure are referred to in the text. A more detailed description of these mechanisms can be found in references [38] and [65].

Why do viruses need of cholesterol-enriched membrane micro-domains? The main reason, but not the unique one, for such requirement of cholesterol is considered to be that this molecule provides the curvature that is stipulated for efficient membrane fusion $[24,25]$. In influenza A virus (IAV), cholesterolenriched domains in the host cell membrane were found to enhance virus entry efficiency, but not rate, in a receptor-independent manner, a feature that leads the researchers to suggest that cholesterol improved membrane fusion by altering the membrane curvature [26]. Diverse studies have shown that lowering the cholesterol content in the cell, either by sequestering it or by means of synthesis inhibitory procedures, the virus entry is negatively affected, thus halting virus infection [14,24,27]. Viruses subverts the cholesterol biosynthetic pathway in their own benefit at the level of the sterol 
regulatory element binding protein (SREBP), the S1 protein (S1P) or the cholesterol efflux regulatory protein (ABCA1), mechanisms that have been studied in different enveloped viruses like SARS-CoV, the hepatitis $\mathrm{C}$ virus (HCV), the human immunodeficiency virus (HIV), hantaviruses, the Dengue virus (DENV) and the West Nile virus (WNV). Therefore, drugs that drop the SREBP, S1P or ABCA1, enzymatic/transport activity have been suggested as potential treatments to ameliorate the virus infection pathology [20,2731]. Another mechanism bound to cholesterol metabolism during viral infection is its delivery through lipid droplets that associate with autophagosomes, a process known as lipophagy, and which requires the activation of the AMP kinase/mTOR axis [32,33]. Some viral proteins have been identified to be implicated in this process through which the virus gets the required cholesterol to be delivered to the membranes of the replication complexes [33-36]. Additional pathways of the lipid metabolism like the fatty acid synthesis and fatty acid $\beta$-oxidation are also modified by the virus for its own profit.

\section{Cholesterol-related antiviral activity of the immune} system: Immediately after viral infection, the innate immune system reacts to halt the virus replication and budding. The lung injures caused by the cytokine storm in SARS-CoV-2 infection has had deleterious and even lethal outcomes during the initial period of the COVID-19 outbreak. However, a softer and poorly deleterious antiviral reaction of the innate immune system is triggered through the interferon- $\beta$ (IFN$\beta$ ). In positive single stranded RNA (ssRNA+) viruses, IFN- $\beta$ has been shown to antagonize the formation of the replication organelle membranes, thus avoiding virus replication [37]. The cholesterol biosynthesis is downregulated by IFN- $\beta$ at the step of the protein SREBP2 of the mevalonate-isoprenoid branch (Figure 2, scheme D), where statins act as well [28]. A primary route through which IFN- $\beta$ interferes the mevalonateisoprenoid branch of the sterol biosynthesis in the host cell has been shown to be inducing microRNAs that inhibit SREBP2 activity [38,39]. Viperin (virus inhibitory protein, endoplasmic reticulum-associated, IFN-inducible) mediates the antiviral activity after its induction by IFN- $\beta$ in macrophages through the interferon regulatory factor 3 (IRF3). The antiviral activity of viperin is related to the reduction of the cholesterol/sphingomyelin supply to the membranes, a mechanism in which upstream regulation by Tolllike receptor 4 (TLR4) is involved [40]. Accordingly, pharmacological treatment with interferon has been proposed in diverse studies to help ameliorating the viral infectivity.

Another interferon-related mechanism directly associated to cholesterol is that pointed out by Wang et al. in regard to SARS-CoV-2 [41]. These authors have shown that 25 -hydroxy-cholesterol $(25 \mathrm{HC})$ may inhibit membrane fusion and, consequently, virus entry, through activation of the acyl-CoA:cholesterol acyl transferase (ACAT), which leads to cholesterol depletion in the plasma membrane. $25 \mathrm{HC}$ is overproduced in COVID-19 patients. The viral inhibitory capacity of $25 \mathrm{HC}$ has been demonstrated for a number of viruses, but the metabolic routes involved in the inhibitory effect remained elusive. 25hydroxy-cholesterol is formed from cholesterol by the cholesterol 25-hydroxylase enzyme, which is induced after SARS-CoV-2 infection through interferonstimulated genes (ISGs).

Cholesterol reduction by statins as antiviral treatment: The role that cholesterol plays in 
cardiovascular disease was unveiled in the second half of the $20^{\text {th }}$ century, and it was named the "lipid hypothesis". The "lipid hypothesis" is well stablished nowadays as a major risk for heart attacks and other cardiovascular diseases even though scepticism still exists among certain groups and health professionals [6]. In order to struggle against this health risk, the Japanese Akira Endo started a research at the onset of the $1970^{\text {th }}$ decade for development of a pharmacological treatment. The Akira Endo research team was able to isolate a compound from the fungus Penicillium citrinum that inhibited the mevalonate pathway at the step of the enzyme HMG-CoA reductase (3-hydroxy-3-methyl-glutaryl-CoA reductase), the key enzyme in the cholesterol and isoprenoid biosynthesis, and they named mevastatin such a compound. However, this compound had deleterious secondary effects on human health and was never marketed. Some years later-on, researchers of the pharma Merck \& Co could isolate a compound, which they named lovastatin, from the fungus Aspergillus terreus, with not so negative secondary effects as mevastatin but which inhibited quite efficiently the HMG-CoA reductase (Figure 2, scheme E). Other statins have been developed afterwards, these including atorvastatin, fluvastatin, pitavastatin, pravastatin, rosuvastatin, and simvastatin, which may reduce LDL cholesterol content in blood by up to $50 \%$ [42] (see also Human Metabolome DataBase at https://hmdb.ca/metabolites). Only simvastatin is included in the World Health Organization (WHO) List of Essential Medicines. Nonetheless, in spite of their beneficial goals in lowering blood cholesterol, they have also negative effects on the human body and may result toxic above certain doses. These side effects are muscle pain or even severe damage to muscle cells, increased risk of diabetes mellitus type 2, abnormal levels of circulating hepatic enzymes, and depressive mood alterations [43-45].

Given the capability of statins to inhibit the cholesterol biosynthesis, such type of drugs is currently used in research focused on viral infection mechanisms. At the COVID-19 onset, the use of statins, and other cholesterol modifying compounds, was proposed to reduce the SARS-CoV-2 infection capacity, encouraging active research on discerning the healing capacity of lipophilic and hydrophilic statins [46]. Specific statins are recommended for HIV patients in order to treat the disease-associated dyslipidaemia [47]. At present, the use of statins is still claimed for treating COVID-19 disease $[12,48]$. Lu et al. had shown for SARS-CoV-1 that depletion of cholesterol triggered the displacement of ACE2 from lipid-rafts to non-raft domains of the membrane, featuring in this way inefficient the viral entry mechanism [49]. Besides lowering cholesterol, the pleiotropic benefits of statins extend to antiinflammatory, immunomodulatory, and antithrombotic properties, they likely playing a significant positive role regarding the amelioration of the cytokine storm and the atherothrombotic complications observed in those patients needing intensive care unit (ICU) admission [20]. Indeed, the COVID-19 pathology resembles to some extent and share traits with the cardiovascular disease [50]. In an in silico study, the antiviral effect of pitavastatin, and to a lesser extent of other statins, was found to be related to disruption of the viral protease, thus decreasing the maturing of viral glycoproteins and replication [51]. Nonetheless, it has been shown that the positive effect of statin treatment could depend upon the disease stage, such effect being more beneficial at the first stages of the disease. 
Phytosterols, diet and exercise: Even though diet cannot prevent infection by SARS-CoV-2 or other viruses at all, an adequate nutrition may help facing the pathological outcomes of the COVID-19 and other viral diseases [52-56]. Regarding cholesterol, a diet that reduces the cholesterol and triglyceride intake while increasing the unsaturated fatty acid (PUFA) intake may help the body to counteract the required extra-energy and viral subversion of the lipid metabolism [57]. As pointed out above, viral hijacking of the lipid metabolism promotes increased synthesis of cholesterol and saturated fatty acids [14], a fact that provokes shortage of cell lipid requirements, and, consequently, replenishing the body's PUFA demand is of concern. In laboratory experiments, the main PUFA, that is arachidonic acid (AA), eicosapentaenoic acid (EPA) and docosahexaenoic acid (DHA), have shown capability to inhibit enveloped virus proliferation during infection $[58,59]$. Additionally, adequate supply of micronutrients is essential for the proper activity of some enzymes, especially those involved in the functions of the innate immune cells $[53,54,60,61]$. Regular exercise is demonstrated to lower the LDL and to rise the HDL, even though with a variable effect between men and women, besides fostering the immune system response [62]. Therefore, a healthy style of life, this including appropriate nutrition and physical state, is likely to make one less susceptible to infection and to augment the survival probability after infection.

Provision to the body of micronutrients and phytochemicals with physiological action through plant extract intake is a current practice in Asian countries according to Herbal Medicine [63-65]. The use of plant derived compounds has been claimed to ameliorate the pathological effects of viral infection during the COVID-19 pandemic [63]. Regarding mechanisms to lower circulating cholesterol, intake of phytosterol and phytostanol concentrates is considered an acceptable dietary supplement (functional foods) to those ingested through vegetables, and compatible with natural practices [66-68]. They are also added to commercial processed foods worldwide and considered safe. Phytosterols act reducing the cholesterol absorption in the gut, that is through a "dilution effect" (Figure 2, scheme F). A daily dose of 3.4 to $5.2 \mathrm{~g}$ in esterified form is recommended by Food and Agriculture Organization of the United Nations (FAO) [66], even though it seems that a dose above $3 \mathrm{~g} /$ day has no a remarkable improvement in cholesterol reduction.

Phytosterols have a chemical structure similar to this of cholesterol, differing only in the aliphatic chain (Figure 3). Their function in plant membranes resembles that of cholesterol in animal membranes. However, phytosterols cannot replace cholesterol in animal membranes and, therefore, the dilution effect in the intestinal absorption is which helps reducing cholesterol levels. Phytostanols are rendered by hydrogenation of the phytosterol double bond. In nature (vegetable oils, nuts and cereals, for instance), they are present as free sterols, as sterol-glucosides and as sterol-esters. A typical western diet contains $300-400 \mathrm{mg} /$ day of plant sterols [69-71], which is below the dose recommended ( $\geq 2 \mathrm{~g} /$ day) to elicit a significant reduction (c.a. 10\%) in the cholesterol level, mainly LDL cholesterol. However, it seems that above $3 \mathrm{~g} /$ day there is not higher cholesterol reduction, and the degree of the effect is likely to depend on both the sterol form and the food matrix in which phytosterols are supplemented [68-70]. In clinical nutrition, supplementary phytosterols are considered a safe practice to avoid raising the statin dose $[64,71]$. A mathematical model was developed 
by Eussen et al. (2011) to assess the expected reduction in circulating (LDL-) cholesterol according to given physiological parameters under combined use of statins (atorvastatin) and phytosterols, the model forecasting 8-9\% cholesterol reduction with 2 g/day phytosterol intake [72].

In addition to cholesterol lowering, a potential capacity of phytosterols to modulate the immune system response has been suggested, although contradictory results have been reported in different trials on this issue, in particular regarding markers of inflammation [69]. The sterol action on immune function is thought to be bound to the increase in T helper 1 (Th1) cell activity as assessed by the IFN- $\gamma$ concentration, whereas Th2 cell over-activity is observed in HIV patients and elderly people.
Nonetheless, the decrease in markers of inflammation might be a side effect of the cholesterol reduction. The influence of $\beta$-sitosterol (Figure 3 ), the most abundant form in human serum (about $6 \mu \mathrm{m}$ ), on inflammation caused by influenza $A$ virus (IAV) infection was recently reported by Zhou et al. [73] These authors found that $\beta$-sitosterol positively diminished inflammation by down-regulating the retinoic acid-inducible gene I (RIG-I) signalling pathway and decreasing the IFN production. As a consequence of this action, expression of COX-2 and the proinflammatory prostaglandin PGE2 were also decreased. Hence, the authors conclude that preadministration of $\beta$-sitosterol protected mice from lethal IAV infection.

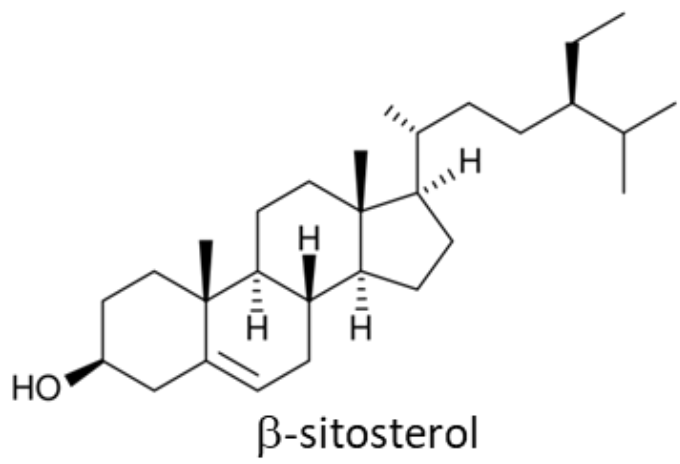

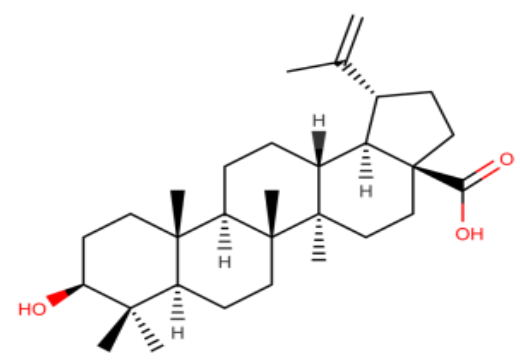

Betulinic acid

Figure 3. Chemical structures of one well-known phytosterol ( $\beta$-Sitosterol) and the pentacyclic triterpenoid Betulinic acid.

A new mechanism through which the phytosterols could inhibit virus infectivity was shown for the betulinic acid (Figure 3) derivative Bevirimat (https://pubchem.ncbi.nlm.nih.gov/compound/Bevir imat\#section=Pharmacology-and-Biochemistry). This drug was developed against the HIV, but clinical trials were halted due to their poor clinical applicability as a consequence of its very low absorption in the small intestine, in addition to poor effectivity in 50\% HIV patients with polymorphisms in the Gag protein. Bevirimat acts by binding to the virus protease Gag and inhibiting virion maturation, which leads to budding of non-infective viral particles. A variety of betulinic acid derivatives with higher maturation inhibition effectivity have been developed since then 
[74]. In addition to phytosterols, other natural compounds from herbal medicine have been shown to have antiviral properties. For instance, emodin inhibits the $3 a$ ion channel protein of SARS-CoV-1 [75]; cepharanthin and valinomycin are lipoxygenase inhibitors against SARS-CoV-1 infection [76]; and plant lectins were found to impede SARS-CoV-1 binding and budding [77]. Nonetheless, in order to assess whether phytosterols, and other natural plant derived compounds, may be considered functional foods against viral infection, more research on their activity beyond the "dilution effect" is devoted, in particular regarding the pathways through which the metabolism may be positively intervened, and the recent COVID-19 outbreak is expected to promote such research.

\section{CONCLUSIONS}

Even though vaccines against SARS-CoV-2 have already been developed and they are clinically applied worldwide at present (January 2021), treatments to ameliorate the pathological effects of COVID-19 and possible further virus-driven pandemics are of concern. In this regard, the use of natural products to prevent or positively counteract the viral disease and post-infection side effects would be welcome for clinical intervention. Within a healthy style of life, phytosterols intake are amongst the compounds that might account for such purpose in addition to provide certain protection against cardiovascular diseases by reducing the cholesterol levels and their immunomodulatory effect.

List of abbreviations: COVID: coronavirus infectious disease, VLDL: very low density lipoprotein, LDL: low density lipoprotein, HDL: high density lipoprotein, NLM-NIH: National Library of Medicine of the National Institutes of Health, RNA: Ribonucleic acid,
HIV: human immunodeficiency virus, ACE2: angiotensin converting enzyme 2, SARS-CoV: severe acute respiratory syndrome coronavirus, SREBP: sterol regulatory element binding protein, SR-B1: scavenger receptor B type 1, IAV: influenza A virus, ABCA: ATP-binding cassette transporter or cholesterol efflux regulatory protein, $\mathrm{HCV}$ : hepatitis $\mathrm{C}$ virus, DENV: dengue virus, WNV, West-Nile virus, AMP: adenosine monophosphate, mTOR: mechanistic target of rapamycin (protein), IFN: interferon, Viperin: virus inhibitory protein, endoplasmic reticulum-associated, IFN-inducible, IRF: interferon regulatory factor, TLR: Toll-like receptor, 25HC: 25-hydroxy-cholesterol, ACAT: acylCoA:cholesterol acyl transferase, ISG: interferon stimulated gene, HMG-CoA: 3-hydroxy-3-methylglutaryl-COA (reductase), WHO: World Health Organization, PUFA: polyunsaturated fatty acid, AA: arachidonic acid, EPA: eicosapentaenoic acid, DHA: docosahexaenoic acid, FAO: Food and Agriculture Organization of the United Nations, Th: Thelper (cell), COX-2: cyclooxygenase-2, PGE: prostaglandin E.

Competing interests: The author has a researcher position in the Spanish National Council of Research (Consejo Superior de Investigaciones Científicas, CSIC) of Spain. Its main research focus is UPLC-MS based Lipidomics, and he has collaborated with different groups in relation to the functional capacity of lipids.

Authors' contribution: Olimpio Montero has conceived, written the manuscript text and drawn the figures.

Acknowledgements and funding: The author has not received any funding to support the writing of this manuscript 


\section{REFERENCES:}

1. Ravnskov U, Diamond DM, Hama R, Hamazaki T, Hammarskjöld B, Hynes $\mathrm{N}$, et al. Lack of an association or an inverse association between low-density-lipoprotein cholesterol and mortality in the elderly: a systematic review. BMJ Open 2016, 6:e010401.

2. Soliman G. Dietary Cholesterol and the Lack of Evidence in Cardiovascular Disease. Nutrients 2018, 10:780.

3. Tikhonoff V, Casiglia E, Mazza A, Scarpa R, Thijs L, Pessina $A C$, et al. Low-Density Lipoprotein Cholesterol and Mortality in Older People: LDL-C AND MORTALITY IN OLDER PEOPLE. J Am Geriatr Soc 2005, 53:2159-2164.

4. Zampelas, Magriplis. New Insights into Cholesterol Functions: A Friend or an Enemy?. Nutrients 2019, 11:1645.

5. Armitage J, Baigent C, Barnes E, Betteridge DJ, Blackwell $L$, Blazing $M$, et al. Efficacy and safety of statin therapy in older people: a meta-analysis of individual participant data from 28 randomised controlled trials. The Lancet 2019, 393:407-415.

6. Goldstein JL, Brown MS. A Century of Cholesterol and Coronaries: From Plaques to Genes to Statins. Cell 2015, 161:161-172.

7. Morgan AE, Mooney KM, Wilkinson SJ, Pickles NA, Mc Auley MT. Cholesterol metabolism: A review of how ageing disrupts the biological mechanisms responsible for its regulation. Ageing Res Rev 2016, 27:108-124.

8. Simons K, Ikonen, E. How Cells Handle Cholesterol Science 2000, 290:1721-1726.

9. Howe V, Sharpe L, Alexopoulos SJ, Kunze SV, Chua NK, Li $D$, et al. Cholesterol homeostasis: How do cells sense sterol excess?. Chem Phys Lipids 2016, 199:170-178.

10. Ohvo-Rekilä et al. H. Cholesterol interactions with phospholipids in membranes. Prog Lipid Res 2002, 41:6697.

11. Lewis GF, Rader DJ. New Insights Into the Regulation of HDL Metabolism and Reverse Cholesterol Transport. Circ Res 2005, 96:1221-1232.

12. Kočar E, Režen T, Rozman D. Cholesterol, lipoproteins, and COVID-19: Basic concepts and clinical applications. Biochim Biophys Acta BBA - Mol Cell Biol Lipids 2021, 1866:158849.

13. Gelissen IC, Brown AJ: An Overview of Cholesterol Homeostasis. In Cholesterol Homeostasis. Edited by Gelissen IC, Brown AJ. New York, NY: Springer New York; 2017: 1-6.

14. Balgoma D, Gil-de-Gómez L, Montero O. Lipidomics Issues on Human Positive ssRNA Virus Infection: An Update. Metabolites 2020, 10:356.

15. Chlanda $\mathrm{P}$, Mekhedov E, Waters H, Schwartz CL, Fischer $E R$, Ryham RJ, et al. The hemifusion structure induced by influenza virus haemagglutinin is determined by physical properties of the target membranes. Nat Microbiol 2016 $1: 16050$
16. Benhaim MA, Lee KK. New Biophysical Approaches Reveal the Dynamics and Mechanics of Type I Viral Fusion Machinery and Their Interplay with Membranes. Viruses 2020, 12:413.

17. Sousa IP, Carvalho CAM, Gomes AMO. Current Understanding of the Role of Cholesterol in the Life Cycle of Alphaviruses. Viruses 2020, 13:35.

18. Nieto-Garai JA, Arboleya A, Otaegi S, Chojnacki J, Casas J, Fabriàs $G$, et al. Cholesterol in the Viral Membrane is a Molecular Switch Governing HIV-1 Env Clustering. Adv Sci 2020, 2003468.

19. Lu Y, Liu DX, Tam JP. Lipid rafts are involved in SARS-CoV entry into Vero E6 cells. Biochem Biophys Res Commun 2008, 369:344-349.

20. Radenkovic D, Chawla S, Pirro M, Sahebkar A, Banach M. Cholesterol in Relation to COVID-19: Should We Care about It? J Clin Med 2020, 9:1909.

21. Osuna-Ramos JF, Reyes-Ruiz JM, del Ángel RM. The Role of Host Cholesterol During Flavivirus Infection. Front Cell Infect Microbiol 2018, 8:388.

22. Lee $\mathbf{W}$, Ahn JH, Park HH, Kim HN, Kim H, Yoo Y, et al. COVID-19-activated SREBP2 disturbs cholesterol biosynthesis and leads to cytokine storm. Signal Transduct Target Ther 2020, 5:186.

23. Wei C, Wan L, Yan Q, Wang X, Zhang J, Yang X, et al. HDLscavenger receptor $B$ type 1 facilitates SARS-CoV-2 entry. Nat Metab 2020, 2:1391-1400.

24. Harrison SC. Viral membrane fusion. Virology 2015, 479480:498-507.

25. Meher G, Bhattacharjya S, Chakraborty H. Membrane Cholesterol Modulates Oligomeric Status and PeptideMembrane Interaction of Severe Acute Respiratory Syndrome Coronavirus Fusion Peptide. J Phys Chem B 2019, 123:10654-10662.

26. Liu KN, Boxer SG. Target Membrane Cholesterol Modulates Single Influenza Virus Membrane Fusion Efficiency but Not Rate. Biophys J 2020, 118:2426-2433.

27. Yuan S, Chu H, Chan JF-W, Ye Z-W, Wen L, Yan B, et al. SREBP-dependent lipidomic reprogramming as a broadspectrum antiviral target. Nat Commun 2019, 10:120.

28. Blanc M, Hsieh WY, Robertson KA, Watterson S, Shui G, Lacaze $P$, et al. Host Defense against Viral Infection Involves Interferon Mediated Down-Regulation of Sterol Biosynthesis. PLoS Biol 2011, 9:e1000598.

29. Petersen J, Drake MJ, Bruce EA, Riblett AM, Didigu CA, Wilen $\mathrm{CB}$, et al. The Major Cellular Sterol Regulatory Pathway Is Required for Andes Virus Infection. PLoS Pathog 2014, 10:e1003911.

30. Kleinfelter LM, Jangra RK, Jae LT, Herbert AS, Mittler E, Stiles KM, et al. Haploid Genetic Screen Reveals a Profound and Direct Dependence on Cholesterol for Hantavirus Membrane Fusion. mBio 2015, 6:e00801-15.

31. Abu-Farha M, Thanaraj TA, Qaddoumi MG, Hashem A, Abubaker J, Al-Mulla F. The Role of Lipid Metabolism in 
COVID-19 Virus Infection and as a Drug Target. Int J Mol Sci 2020, 21:3544.

32. Heaton NS, Randall G. Dengue Virus-Induced Autophagy Regulates Lipid Metabolism. Cell Host Microbe 2010, 8:422-432.

33. Randall G. Lipid Droplet Metabolism during Dengue Virus Infection. Trends Microbiol 2018, 26:640-642.

34. Mujawar Z, Rose H, Morrow MP, Pushkarsky T, Dubrovsky L, Mukhamedova $\mathrm{N}$, et al. Human Immunodeficiency Virus Impairs Reverse Cholesterol Transport from Macrophages. PLoS Biol 2006, 4:e365.

35. Cui HL, Grant A, Mukhamedova N, Pushkarsky T, Jennelle L, Dubrovsky L, et al. HIV-1 Nef mobilizes lipid rafts in macrophages through a pathway that competes with ABCA1-dependent cholesterol efflux. J Lipid Res 2012, 53:696-708.

36. Crawford SE, Hyser JM, Utama B, Estes MK. Autophagy hijacked through viroporin-activated calcium/calmodulin-dependent kinase kinase- signaling is required for rotavirus replication. Proc Natl Acad Sci 2012, 109:E3405-3413.

37. Oudshoorn D, van der Hoeven B, Limpens RWAL, Beugeling C, Snijder EJ, Bárcena M, et al. Antiviral Innate Immune Response Interferes with the Formation of Replication-Associated Membrane Structures Induced by a Positive-Strand RNA Virus. mBio 2016, 7:e01991.

38. Robertson KA, Ghazal P. Interferon Control of the Sterol Metabolic Network: Bidirectional Molecular CircuitryMediating Host Protection. Front Immunol 2016, 7:634.

39. Robertson KA, Hsieh WY, Forster T, Blanc M, Lu H, Crick PJ, et al. An Interferon Regulated MicroRNA Provides Broad Cell-Intrinsic Antiviral Immunity through Multihit Host-Directed Targeting of the Sterol Pathway. PLOS Biol 2016, 14:e1002364.

40. Tang H-B, Lu Z-L, Wei X-K, Zhong T-Z, Zhong Y-Z, Ouyang $L-X$, et al. Viperin inhibits rabies virus replication via reduced cholesterol and sphingomyelin and is regulated upstream by TLR4. Sci Rep 2016, 6:30529.

41. Wang S, Li W, Hui H, Tiwari SK, Zhang Q, Croker BA, et al. Cholesterol 25-Hydroxylase inhibits SARS -CoV-2 and other coronaviruses by depleting membrane cholesterol. EMBO J 2020, 39:e106057.

42. Alenghat FJ, Davis AM. Management of Blood Cholesterol. JAMA 2019, 321:800.

43. Ramkumar S, Raghunath A, Raghunath S. Statin Therapy: Review of Safety and Potential Side Effects. Acta Cardiol Sin 2016, 32:631-639.

44. Pinal-Fernandez I, Casal-Dominguez M, Mammen AL. Statins: pros and cons. Med Clínica 2018, 150:398-402.

45. Toth, Peter P B Maciej. Statins: Then and Now. Methodist Debakey Cardiovasc J 2019, 15:23-31.

46. Schmidt NM, Wing PAC, McKeating JA, Maini MK. Cholesterol-modifying drugs in COVID-19 Oxf Open Immunol 2020, 1:iqaa001.
47. Borges R de P, Degobi NAH, Bertoluci MC. Choosing statins: a review to guide clinical practice. Arch Endocrinol Metab 2020, 64:6

48. Ganjali S, Bianconi V, Penson PE, Pirro M, Banach M, Watts GF, et al. Commentary: Statins, COVID-19, and coronary artery disease: killing two birds with one stone. Metabolism 2020, 113:154375.

49. Lu Y, Liu DX, Tam JP. Lipid rafts are involved in SARS-CoV entry into Vero E6 cells. Biochem Biophys Res Commun 2008, 369:344-349.

50. Pimentel LL, Rodríguez-Alcalá LM. Cholesterol, inflammation, and phospholipids: COVID-19 share traits with cardiovascular disease. Biochim Biophys Acta BBA Mol Cell Biol Lipids 2021, 1866:158839.

51. Reiner Ž, Hatamipour M, Banach M, Pirro M, Al-Rasadi K, Jamialahmadi $\mathrm{T}$, et al. Statins and the COVID-19 main protease: in silico evidence on direct interaction. Arch Med Sci 2020, 16:490-496.

52. Haslberger A, Jacob U, Hippe B, Karlic H. Mechanisms of selected functional foods against viral infections with a view on COVID-19: Mini review. Funct Foods Health Dis 2020, 10:195.

53. Iriondo-DeHond A, Montero $\mathrm{O}$, Revilla $\mathrm{Y}$, Uranga JA, Abalo $R$, del Castillo $M D$,: Nutritional support: another treatment for fighting COVID-19. In Funct Foods Viral Dis. Volume 8. 1st edition. Edited by Martirosyan D. Dallas, Texas, USA: Food Science Publisher; 2020:93-126.

54. Martirosyan D, Santoro A, Malcom S,: Enhancing the elderly's immune system for healthy aging, to fight chronic and viral disease including Covid-19. In Funct Foods Viral Dis. Volume 8. 1st edition. Edited by Martirosyan D. Dallas, Texas, USA: Food Science Publisher; 2020:7-42.

55. Emerald M: Nutrients in prevention and maintenance of COVID-19 and other viral diseases. In Funct Food Viral Dis. Volume 8. 1st edition. Edited by Martirosyan D. Dallas, Texas, USA: Food Science Publisher; 2020:175-202.

56. Hartley L, Igbinedion E, Holmes J, Flowers N, Thorogood $\mathrm{M}$, Clarke A, et al. Increased consumption of fruit and vegetables for the primary prevention of cardiovascular diseases. Cochrane Database Syst Rev . 2013, 6:CD009874.

57. Welty FK. Dietary treatment to lower cholesterol and triglyceride and reduce cardiovascular risk. Curr Opin Lipidol 2020, 31:206-231.

58. Yan B, Chu H, Yang D, Sze K-H, Lai P-M, Yuan S, et al. Characterization of the Lipidomic Profile of Human Coronavirus-Infected Cells: Implications for Lipid Metabolism Remodeling upon Coronavirus Replication. Viruses 2019, 11:73.

59. Das U.N. Can Bioactive Lipids Inactivate Coronavirus COVID-19? Arch Med Res 2020, 51:282-286.

60. 60. Hamer DH, Sempértegui $F$, Estrella $B$, Tucker KL, Rodríguez A, Egas J, et al. Micronutrient Deficiencies Are Associated with Impaired Immune Response and Higher 
Burden of Respiratory Infections in Elderly Ecuadorians. J Nutr 2009, 139:113-119.

61. Pang G, Xie J, Chen Q, Hu Z. How functional foods play critical roles in human health. Food Sci Hum Wellness 2012, 1:26-60.

62. Skoumas J, Pitsavos C, Panagiotakos DB, Chrysohoou C, Zeimbekis A, Papaioannou I, et al. Physical activity, high density lipoprotein cholesterol and other lipids levels, in men and women from the ATTICA study. Lipids Health Dis 2003, 2:3.

63. Glatthaar-Saalmüller B, Rauchhaus $U$, Rode $S$, Haunschild J, Saalmüller A. Antiviral activity in vitro of two preparations of the herbal medicinal product Sinupret ${ }^{\circledR}$ against viruses causing respiratory infections. Phytomedicine 2011, 19:1-7.

64. Fernández-Oliva A, Ortega-González P, Risco C. Targeting host lipid flows: Exploring new antiviral and antibiotic strategies. Cell Microbiol 2019, 21:e12996.

65. Lin L-T, Hsu W-C, Lin C-C. Antiviral Natural Products and Herbal Medicines. J Tradit Complement Med 2014, 4:2435.

66. Cantrill, R. PHYTOSTEROLS, PHYTOSTANOLS AND THEIR ESTERS Chemical and Technical Assessment $69^{\text {th }}$ JECFA (CTA). 2008.

67. Télessy IG: Nutraceuticals. In Role Funct Food Secur Glob Health. Volume 1. $1^{\text {st }}$ edition. Edited by Singh RB, Watson RR, Takahashi T.. Elsevier Inc.; 2019:409-421.

68. Plat J, Baumgartner S, Vanmierlo T, Lütjohann D, Calkins $\mathrm{KL}$, Burrin DG, et al. Plant-based sterols and stanols in health \& disease: Consequences of human development in a plant-based environment? Prog. Lipid Res 2019, 74:87-102.

69. Brüll F, Mensink RP, Plat J. Plant sterols: functional lipids in immune function and inflammation? Clin Lipidol 2009, 4:355-365.
70. Gupta AK, Savopoulos CG, Ahuja J, Hatzitolios AI. Role of phytosterols in lipid-lowering: current perspectives. QJM 2011, 104:301-308.

71. Pascual Fuster V. Utilidad de los esteroles vegetales en el tratamiento de la hipercolesterolemia. Nutr Hosp 2017, 34(Suppl 4):62-67.

72. Eussen SR, Rompelberg $\mathrm{CJ}$, Klungel $\mathrm{OH}$, van Eijkeren JC. Modelling approach to simulate reductions in LDL cholesterol levels after combined intake of statins and phytosterols/-stanols in humans. Lipids Health Dis 2011, 10:187.

73. Zhou B, Li J, Liang X, Pan X, Hao Y, Xie P, et al. $\beta$-sitosterol ameliorates influenza $A$ virus-induced proinflammatory response and acute lung injury in mice by disrupting the cross-talk between RIG-I and IFN/STAT signaling. Acta Pharmacol Sin 2020, 41:1178-1196.

74. Hodon J, Borkova L, Pokorny J, Kazakova A, Urban M. Design and synthesis of pentacyclic triterpene conjugates and their use in medicinal research. Eur J Med Chem 2019, 182:111653.

75. Schwarz S, Wang K, Yu W, Sun B, Schwarz W. Emodin inhibits current through SARS-associated coronavirus 3a protein. Antiviral Res 2011, 90:64-69.

76. Karuppannan AK, Wu KX, Qiang J, Chu JJ-H, Kwang J. Natural compounds inhibiting the replication of Porcine reproductive and respiratory syndrome virus. Antiviral Res 2012, 94:188-194.

77. Keyaerts E, Vijgen L, Pannecouque C, Van Damme E, Peumans $W$, Egberink $H$, et al. Plant lectins are potent inhibitors of coronaviruses by interfering with two targets in the viral replication cycle. Antiviral Res 2007, 75:179-187. 